\title{
MAPA INTERATIVO 3D: DESENVOLVIMENTO DO APLICATIVO “OLINDA SOB OS PÉS E NA PALMA DA MÃO”
}

\section{D INTERACTIVE MAP: DEVELOPMENT OF THE APP “OLINDA UNDERFOOT AND IN THE PALM OF THE HAND”}

\author{
Elton Vieira ${ }^{1}$, M.Sc. \\ Paulo Diniz ${ }^{2}$, M.Sc. \\ Nelcy Magdala Moura e Santos, M.Sc. \\ (1) IFPE \\ e-mail:elton.vieira@olinda.ifpe.edu.br \\ (2) IFPE \\ e-mail:paulo.diniz@olinda.ifpe.edu.br \\ (3) IFPE \\ e-mail: nelcy.magdala@olinda.ifpe.edu.br
}

Modelagem 3D, Patrimônio Histórico, Aprendizagem Ubíqua.

Este artigo apresenta o processo de desenvolvimento do aplicativo para dispositivos móveis Olinda sob os Pés e na Palma da Mão, um mapa interativo modelado em 3D, construído com o objetivo de resgatar a relação entre turistas e moradores com a cidade de Olinda-PE e seu patrimônio cultural/histórico/artístico.

\section{D Modeling, Historical Patrimony, u-Learning}

This article presented the mobile app development process of the project "Olinda sob os Pés e na Palma da Mão", a interactive map modeling in $3 D$, constructed whit the goal to rescue a relationship between tourists and local residents of Olinda - Pernambuco and your cultural/historical/artistic patrimony.

\section{Introdução}

As metodologias de ensino foram evoluindo com o passar do tempo. As tecnologias da informação, segundo Moura (2007), revolucionaram o acesso a informação. A onipresença da computação na vida das pessoas, seu custo, conexão com internet e potencial revolucionário é estudada pela Computação Ubíqua (Araújo, 2003).

Quando voltada para a área da educação e o uso da 


\section{$16^{\circ}$ \\ ERGODESIGN USIHC CINAHPA}

$16^{\circ}$ Ergodesign - Congresso Internacional de Ergonomia e Usabilidade de Interfaces Humano Tecnológica: Produto, Informações Ambientes Construídos e Transporte

$16^{\circ}$ USIHC - Congresso Internacional de Ergonomia e Usabilidade de Interfaces Humano Computador

CINAHPA | 2017 - Congresso Internacional de Ambientes Hipermídia para Aprendizagem. computação ubíqua dentro e fora da sala de aula, o termo Aprendizado Ubíquo é utilizado (Parise, 2014). É importante ressaltar que o aprendizado ubíquo não depende das tecnologias computacionais para existir, porém seu potencial é acrescido com a utilização delas. Um dos pilares da aprendizagem ubíqua é o processo espontâneo e assistemático do ensino, fora dos padrões estáticos da sala de aula (Santaella, 2013).

Baseado nesse contexto, foi idealizado o projeto "Olinda sob os Pés e na Palma da Mão", que tem como objetivo a construção de uma Mapa Interativo Digital em 3D da cidade histórica de Olinda. A dinâmica de mudança das cidades faz que a memória patrimonial seja, por muitas vezes, ignorada pelos turistas e os próprios moradores locais. O projeto tem como apoio teórico os conceitos de computação ubíqua (ubicomp) e aprendizado ubíquo (u-Learning).

\subsection{Fundamentação Teórica}

Terceira maior cidade de Pernambuco, Olinda possui o título de Patrimônio Histórico da Humanidade (UNESCO). As ruas históricas e casario colonial recebem milhares de turistas por ano. O recorte espacial escolhido foi a área da Sé de Olinda, também chamada Alto da Sé, ou ainda genericamente como Cidade Alta. Os prédios da área passaram por diversas intervenções durante os anos (Cabral, 2016), principalmente a Igreja Matriz de São Salvador, como revela a Figura 1.
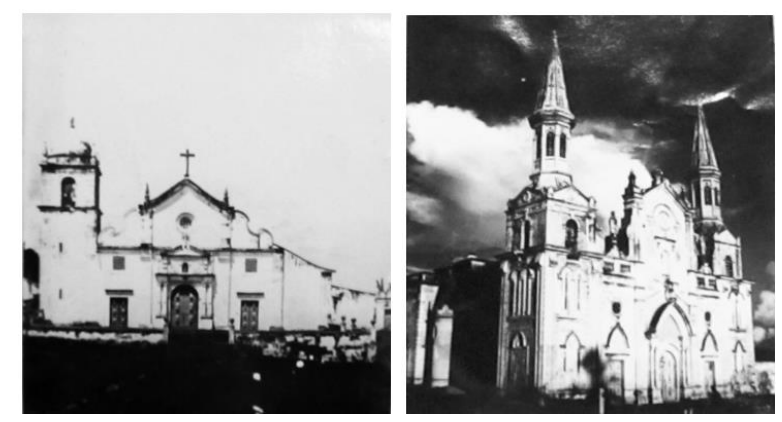
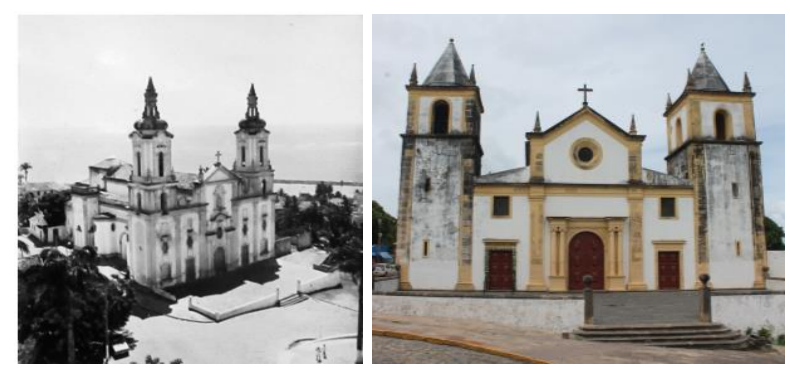

Figura 1: Igreja Matriz de São Salvador (Igreja da Sé de Olinda) em 4 estilos arquitetônico diferenças: barroco, neogótico, eclético e maneiristas..

Jácome et al, (2013) define o aprendizado ubíquo como processos de aprendizagem apoiado por tecnologias da informação ou comunicação móvel, sensíveis ao contexto do aprendiz e utilizando comunicação sem fio. Ambientes de aprendizado ubíquo tem o objetivo de transformar a Educação a Distância como conhecemos, deixando-a mais versátil. Assim, as ferramentas de aprendizagem deixam de ser parte de um conteúdo curricular específico, e passa a ser parte do comportamento social digital do indivíduo, objetivo principal do Mapa Interativo. O mapa interativo do Alto da Sé é um aplicativo construído para que moradores e turistas conheçam o lugar onde moram/visitam. Registros históricos textuais-imagéticos são disponibilizados, tornando a absorção do conteúdo mais lúdico.

\section{Metodologia}

O processo metodológico foi dividido em quatro etapas: 1- escolha dos edifícios; 2 - pesquisa de imagens históricas e construção dos textos; 3 estudo das proporções imagéticas; 4- modelagem 3D da edificação (Fig. 2). Cada estilo arquitetônico e período de tempo apresenta detalhes construtivos e características únicas, funcionando como um espelho da época em que foi construída. Assim, antes mesmo de se iniciar o processo de modelagem 3D, foi necessária uma consistente pesquisa imagética do sítio histórico. O objetivo é proporcionar ao usuário do mapa aporte visual das versões históricas dos prédios, assim como um breve resumo textual da época em que foram realizadas.
Realização:
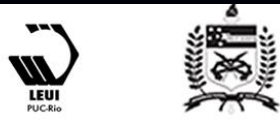


\section{$16^{\circ}$ \\ ERGODESIGN USIHC CINAHPA}

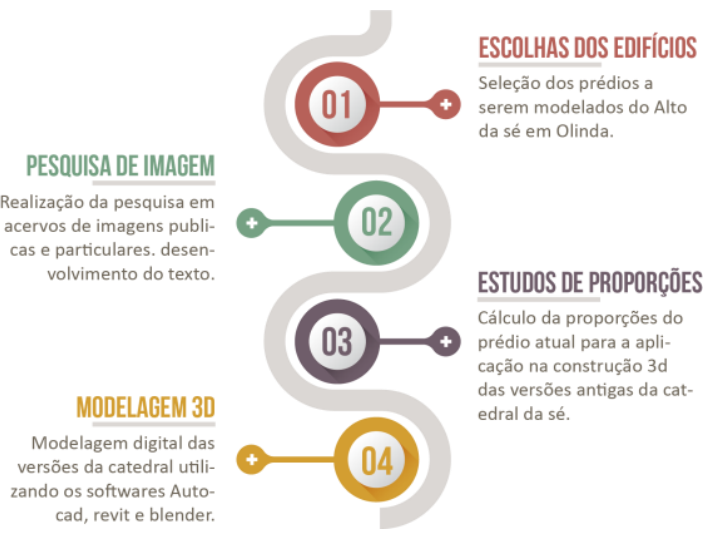

Figura 2: Etapas da Metodologia desenvolvida para o Projeto do Mapa Interativo.

\subsection{Escolha dos edifícios}

Foram escolhidos os prédios mais icônicos do local, deixando de lado as casas particulares e prédios sem grande expressão histórica. A Igreja Matriz de São Salvador foi escolhida como o fio condutor de toda a construção do mapa. Assim, foram selecionados os seguintes prédios: Igreja Matriz de São Salvador, Caixa D'água, Museu de Artes Sacras de Pernambuco, Academia Santa Gertrudes, Observatório e Igreja da Misericórdia. O relevo do local foi desenvolvido a partir de observações de mapas topológicos e softwares de simulação espacial.

\subsection{Pesquisa Histórica-Imagética}

Durante anos, vários os fotógrafos registraram as construções presentes no Alto da Sé. Formais ou informais, parte de coleções particulares ou públicas, a análise de tais imagens fazia-se necessário para o reconhecimento das versões arquitetônicas da construção. Foram utilizadas o acervo físico e digital de imagens da Fundação Joaquim Nabuco (FUNDAJ), Instituto do Patrimônio Histórico e Artístico Nacional (IPHAN) e a da Casa do Patrimônio da cidade de Olinda. Todo o material coletado na FUNDAJ, base principal da coleta, é formado pelo acervo fotográficos de Alexandre Berzin, Franklin Figueiredo, Arnaldo Guedes e Família Cavalcanti Lins. Posteriormente este material foi disponibilizado online para o público. $16^{\circ}$ Ergodesign - Congresso Internacional de Ergonomia e Usabilidade de Interfaces Humano Tecnológica: Produto, Informações Ambientes Construídos e Transporte

$16^{\circ}$ USIHC - Congresso Internacional de Ergonomia e Usabilidade de Interfaces Humano Computador

CINAHPA | 2017 - Congresso Internacional de Ambientes Hipermídia para Aprendizagem.

Em paralelo à pesquisa imagética, foi realizado também uma pesquisa histórica para entender o contexto das construções e reconstruções dos prédios do Alto da Sé. Com isso foi possível construir textos simples para compor a transmissão de conhecimento junto ao aporte visual do mapa.

\subsection{Estudo de Proporções}

Em posse das imagens históricas do Alto da Sé de Olinda, era necessário a verificação das proporções arquitetônicas das suas versões para que a modelagem 3D não pecasse na aplicação de suas dimensões. Para isso, foi tomado como ponto de partida a arquitetura atual dos prédios Alguns elementos da fachada dos prédios seriam o ponto de referência inicial e a base do cálculo de proporção (Fig.3).

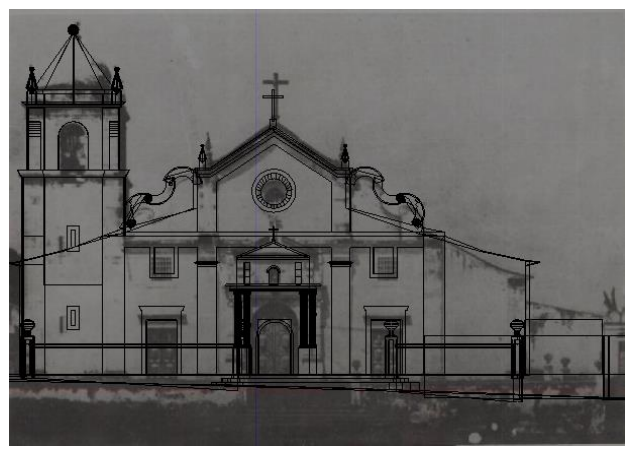

Figura 3: Estudo de Proporções na fachada da Igreja Matriz de São Salvador.

\section{Resultados}

\subsection{Modelagem 3D}

A versatilidade da modelagem 3D se dá a grande quantidade de pesquisa visual durante a execução do projeto, além da utilização de programas computacionais gratuitos, previamente selecionados pela equipe. É importante destacar que os softwares da Suite Autodesk estão gratuitos por 3 anos, disponibilizados aos estudantes e professores, sem distinção, desde que se cadastre no site da Autodesk. A complexidade do trabalho levou a divisão de tarefas entre a equipe do projeto. Cada integrante da equipe de modelagem 3D ficou responsável por prédios em específico. A Igreja Matriz de São Salvador foi considerada o ponto 


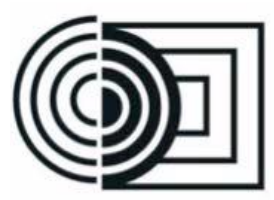

principal do mapa interativo, então foi o primeiro monumento a ser modelado. Todas as suas versões históricas foram desenvolvidas, como exemplificadas nas Figuras 4, 5 e 6.

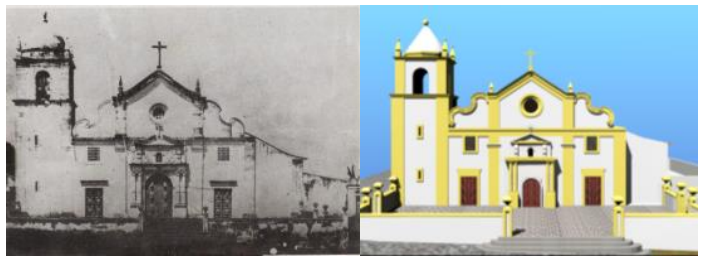

Figura 4: Imagem original e modelagem 3d da versão barroca da fachada da Igreja Matriz de São Salvador de 1910.

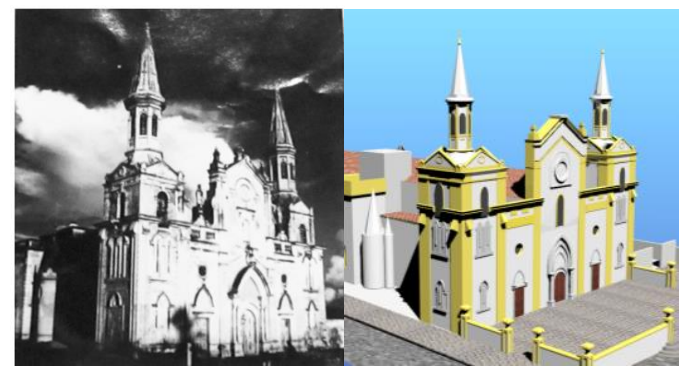

Figura 5: Imagem original e modelagem 3d da versão neogótica da fachada da Igreja Matriz de São Salvador de 1930.

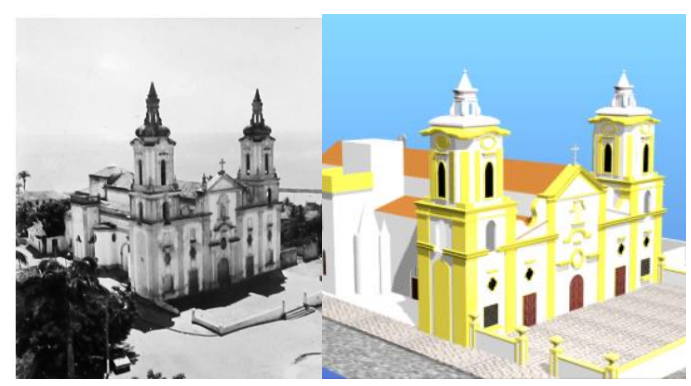

Figura 6: Imagem original e modelagem $3 d$ da versão eclética da fachada da Igreja Matriz de São Salvador de 1984.

Foi desenhada a planta baixa da caixa d'água de Olinda (1937), logo após foram inseridas as dimensões do terreno e os elementos construtivos básicos da edificação. Utilizando o Revit 3D, foi dada a volumetria arquitetônica dos modelos. Contudo, apesar da facilidade na construção arquitetônica dos softwares anteriores, o prédio possui muitos detalhes, então assim passou-se a $16^{\circ}$ Ergodesign - Congresso Internacional de Ergonomia e Usabilidade de Interfaces Humano Tecnológica: Produto, Informações Ambientes Construídos e Transporte

$16^{\circ}$ USIHC - Congresso Internacional de Ergonomia e Usabilidade de Interfaces Humano Computador

CINAHPA | 2017 - Congresso Internacional de Ambientes Hipermídia para Aprendizagem.

utilizar o Blender (Figura 7).
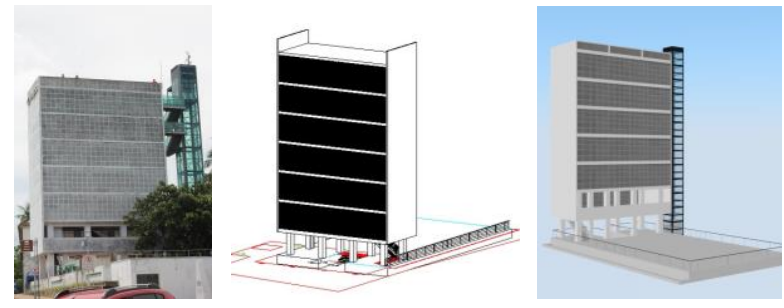

Figura 7: Imagem original e modelagem Caixa D'água de Olinda.

O Blender também foi utilizado para a finalização dos prédios da Caixa D'Água e da Igreja Matriz de São Salvador nos 4 estilos arquitetônicos em épocas diferentes. $\mathrm{O}$ software Blender foi utilizado para o desenvolvimento dos outros prédios.

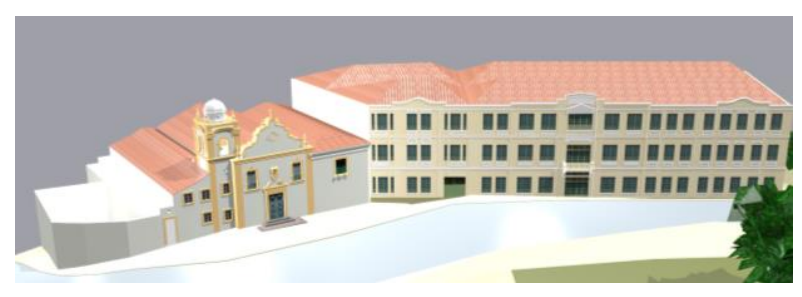

Figura 8: Imagem original e modelagem $3 \mathrm{~d}$ da Igreja da Misericórdia e Academia Santa Gertrudes.

Assim, o Museu de Artes Sacras de Pernambuco e Observatório Astronômico também foram desenvolvidos, separadamente, utilizando apenas as ferramentas da versão 2.73 do Blender.

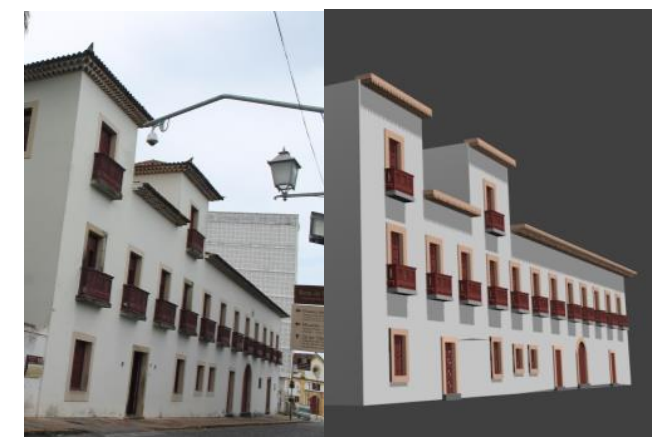

Figura 9: Imagem original e modelagem 3d Museu de Artes Sacras de Pernambuco.

Foram realizadas visitas ao sítio histórico para registro fotográfico para o mapeamento das texturas e observação do relevo acidentado. Por 


\section{$16^{\circ}$ \\ ERGODESIGN USIHC CINAHPA}

fim, quando os modelos digitais de todos os prédios ficaram prontos, houve o processo de estudo topográfico e geolocalização modelos digitais no espaço tridimensional digital.

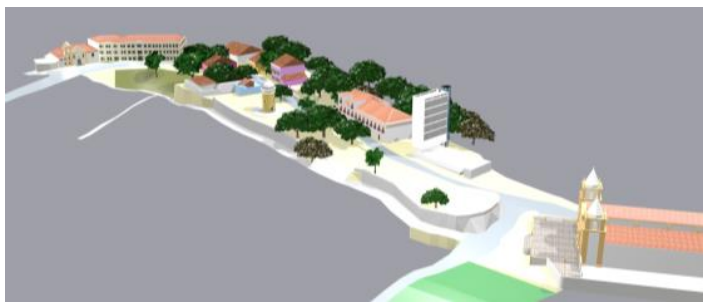

Figura 10: Imagem da modelagem 3d do sítio histórico do Alto da Sé.

\subsection{Desenvolvimento da Interface do Mapa Interativo}

O aplicativo do Mapa Interativo do Alto da Sé de Olinda foi pensado para ser compatível com todos os sistemas operacionais, gratuito, rápido, leve e fácil de utilizar. A tela inicial do aplicativo já apresenta o mapa tridimensional apto para utilização. Assim, o projeto de navegação entre as ferramentas do aplicativo foi projetada para ser simples. A navegação por abas não é neutra e seu estilo visual depende do sistema operacional ao qual é aplicado (NEIL, 2012).

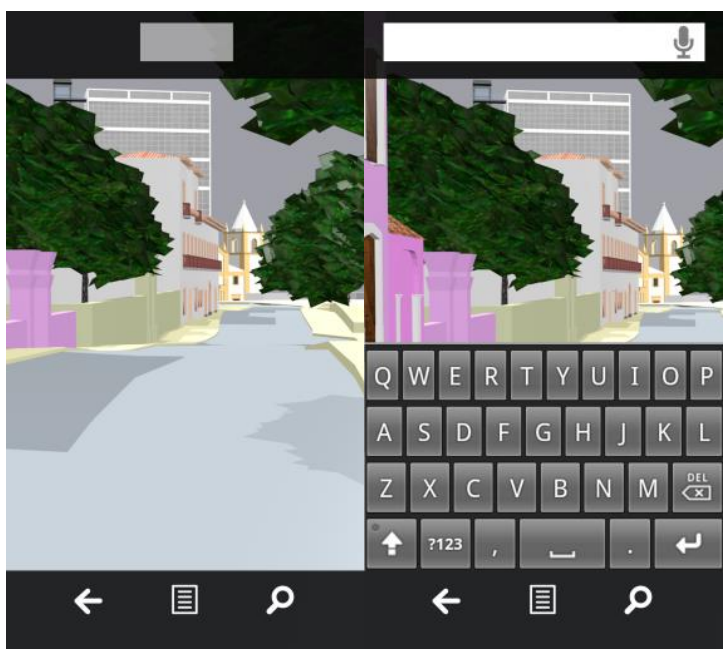

Figura 11: Imagem da Interface da Tela Inicial do Aplicativo do Mapa Interativo. $16^{\circ}$ Ergodesign - Congresso Internacional de Ergonomia e Usabilidade de Interfaces Humano Tecnológica: Produto, Informações Ambientes Construídos e Transporte

$16^{\circ}$ USIHC - Congresso Internacional de Ergonomia e Usabilidade de Interfaces Humano Computador

CINAHPA | 2017 - Congresso Internacional de Ambientes Hipermídia para Aprendizagem.

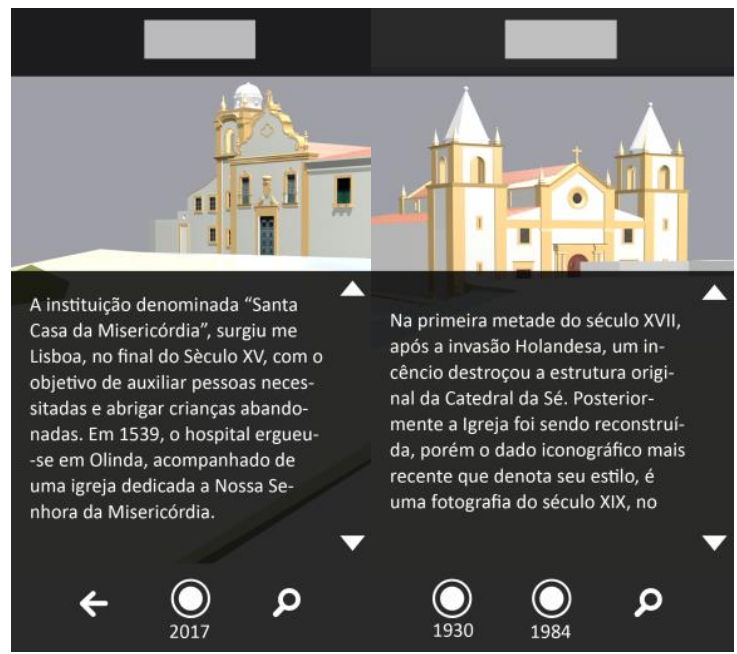

Figura 12: Imagem da Interface da Tela com o texto do resumo histórico do prédio do Aplicativo do Mapa Interativo.

As abas contêm três elementos, as ferramentas de undo e busca apresentam função simples e genérica de qualquer aplicativo. A tela do aplicativo quando acionada a ferramenta de busca utiliza o keyboard padrão do sistema operacional para a digitação do termo da busca. O ícone central da tela de busca é utilizado para demonstrar as informações textuais no aplicativo. O texto foi desenvolvido para que seja fácil e rápido de ler. Ajudando no entendimento e fixação do conhecimento adquirido (Fig. 11). Alguns prédios apresentam versões diferentes das suas fachadas de acordo com as décadas. Cada uma dessa versões possuem aspectos históricos únicos, que serão evidenciados no aplicativo. Nessa tela é possível perceber a mudança nas abas de navegação (Fig. 12). As versões anteriores das fachadas dos prédios poderão ser acessadas através de um swap simples nas abas apresentadas. Os ícones apresentam a data da mudança das fachadas como elemento de informação.

\subsection{Conclusã̃o}

O projeto executado, ora descrito, faz parte do plano de criação do aplicativo do Mapa Virtual do Sítio Histórico de Olinda. Um dos pontos turísticos mais importantes do Estado de Pernambuco, ao qual necessita de ferramentas próximas à população para a perpetuação da sua História
Realização:

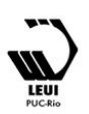




\section{$16^{\circ}$ \\ ERGODESIGN USIHC CINAHPA}

visual e patrimonial.

A partir do que foi desenvolvido, é possível perceber o potencial de utilização do aplicativo para disseminar conhecimento histórico. Esta é uma das bases da aprendizagem ubíqua, onde o ensino ocorre de forma contextualizada e nãoburocrática. O Mapa Interativo possui potencial de utilização tanto no processo de ensino e aprendizagem, quanto no contexto turístico. Faz-se necessário observar que, mesmo com o apoio dos recursos tecnológicos mais avançados e dinâmicos na construção do aplicativo e da modelagem tridimensional, foi enfrentado obstáculos que influenciaram no tempo do projeto e, consequentemente, no resultado do mesmo. Realizar a modelagem tridimensional de um prédio baseado apenas em fotografias antigas é um desafio, pois não há informações exatas de proporções e texturas. A topografia do local também é uma atenuante, inicialmente desconsiderada no desenvolvimento do modelo 3D. Contudo, a metodologia de pesquisa imagética e patrimonial, assim como a modelagem $3 \mathrm{D}$ e desenvolvimento do aplicativo criada e executada pela equipe do projeto, poderá ser replicada na modelagem de outros prédios do Alto da Sé, assim como em diversos projetos que compartilhem o mesmo contexto. Os próximos passos do projeto é realizar a validação junto ao usuário final, a fim de maximizar a eficiência da disseminação do conhecimento implícito no aplicativo.

\section{Referências Bibliográficas}

ARAÚJO, R. B. Computação Ubíqua:

Princípios, Tecnologias e Desafios. XXI Simpósio Brasileiro de Redes de Computadores. Natal - Rio Grande do Norte. 2003.

CABRAL, R. Entre destruições, achados e invenção: a restauração da Sé de Olinda no âmbito do Programa Integrado de Reconstrução das Cidades Históricas do Nordeste. Anais do Museu Paulista. São Paulo. N. Sér. v.24. n.1. p. 181-203. jan.- abr. 2016.

JÁCOME JÚNIOR, Luiz, et al. Uma Extensão do Moodle para Recomendação Ubíqua de Objetos $16^{\circ}$ Ergodesign - Congresso Internacional de Ergonomia e Usabilidade de Interfaces Humano Tecnológica: Produto, Informações Ambientes Construídos e Transporte

$16^{\circ}$ USIHC - Congresso Internacional de Ergonomia e Usabilidade de Interfaces Humano Computador

CINAHPA | 2017 - Congresso Internacional de Ambientes Hipermídia para Aprendizagem.

de Aprendizagem. Revista Renote 10.3, 2012.

LOPES, C. O Ensino De História Na Palma Da Mão: O Whatsapp Como Ferramenta Pedagógica Para Alem Da Sala De Aula. Simpósio Internacional de Educação a Distância. São Carlos - São Paulo. 2016.

MOURA, M.. Design de hipermídia: dos princípios aos elementos. E- book Org: por Martha C. C. Gabriel e Jofre Silva. São Paulo, Rosari: 2007.

NEIL, T. Padrões de Design para Aplicativos Móveis. O'Reilly - Novatec. São Paulo - São Paulo. 2012.

OLIVEIRA, D.; CARVALHO, M.; PAIXÃO, T. Ubiquitous Computing: Gestures Interaction Applied the Learning Disabilities in Process Literacy. Proceedings of the 22nd Brazilian Symposium on Multimedia and the Web. Teresina - Piauí, 2016.

PARISE, D.; PARISE, M. MARAN, V.; BATTISTI, G. U-Learing - O futuro do EAD?. Anais do $3^{\circ}$ SENID. Passo Fundo - Rio Grande do Sul. 2014.

PESQUISA nacional por Amostra de Domicílios 2015. Rio de Janeiro. IBGE. 2015. Disponível em: http://www.ibge.gov.br/home/estatistica/populacao /trabalhoerendimento/pnad2015/default.shtm.

Acessado em: 15 de março de 2017.

\section{SANTAELLA, L. A aprendizagem ubíqua} substitui a educação formal?. Revista de Computação e Tecnologia da PUC-SP. Vol. II. No 1. Pag. 17. 2013.

SILVA, B.; NETO, F.; LEITE, R.; DUTRA, J. Um Ambiente Social Virtual de Auxílio à Aprendizagem Informal na Área de Saúde. Anais dos Workshops do V Congresso Brasileiro de Informática na Educação. Uberlândia - Minas Gerais, 2016.

CULLEN, G. Paisagem Urbana. Lisboa: Edições 70,19 .
Realização:

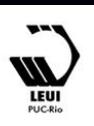

